\title{
Research Article \\ Coupled Fixed Points for Meir-Keeler Contractions in Ordered Partial Metric Spaces
}

\author{
Thabet Abdeljawad, ${ }^{1}$ Hassen Aydi, ${ }^{2}$ and Erdal Karapınar ${ }^{3}$ \\ ${ }^{1}$ Department of Mathematics and Computer Sciences, Çankaya University, 06530 Ankara, Turkey \\ 2 Institut Supérieur d'Informatique et des Technologies de Communication de Hammam Sousse, \\ Université de Sousse, Route GP1, 4011 H. Sousse, Tunisia \\ ${ }^{3}$ Department of Mathematics, Atılım University, İncek, 06836 Ankara, Turkey
}

Correspondence should be addressed to Erdal Karapınar, erdalkarapinar@yahoo.com

Received 18 February 2012; Revised 19 April 2012; Accepted 2 May 2012

Academic Editor: Rafael Martinez-Guerra

Copyright (C) 2012 Thabet Abdeljawad et al. This is an open access article distributed under the Creative Commons Attribution License, which permits unrestricted use, distribution, and reproduction in any medium, provided the original work is properly cited.

In this paper, we prove the existence and uniqueness of a new Meir-Keeler type coupled fixed point theorem for two mappings $F: X \times X \rightarrow X$ and $g: X \rightarrow X$ on a partially ordered partial metric space. We present an application to illustrate our obtained results. Further, we remark that the metric case of our results proved recently in Gordji et al. (2012) have gaps. Therefore, our results revise and generalize some of those presented in Gordji et al. (2012).

\section{Introduction and Preliminaries}

Fixed point theory is an important tool in the study of nonlinear analysis as it is considered to be the key connection between pure and applied mathematics with wide applications in economics, physical sciences, such as biology, chemistry, physics, differential equations, and almost all engineering fields (see, e.g., [1-13]). From the engineering point of view there are numerous problems in adaptive systems where convergence, optimal performance, and stability are key issues. In this direction many case studies with engineering applications can be described by contraction mappings and their fixed point iterations, such as linear and nonlinear filters, image restoration and image retrieval, and in many other areas where this theory helps to describe and/or understand the phenomenon. Indeed, the relaxation in linear systems, and relaxation and stability in neural networks can be analyzed in this light, where examples for a posteriori and normalized learning algorithms for adaptive filters for monophonic and stereophonic echo cancelation can be presented [14, 15]. 
Also it is worth mentioning that Matthews introduced the notion of partial metric space, which provides an area with great potential for the development of fixed point theory, as well as tools of conducting studies on denotational semantics of data-flow networks [16].

As a result it is evident that the importance of fixed point theory cannot be ruled out. Banach fixed point theorem [17] is the cornerstone of this topic. The result of Banach has drawn considerable interest of many authors. There are very different approaches in the study of generalization of a Banach fixed point theorem.

One of the interesting generalizations was announced by Matthews [16]. The author introduced the notion of partial metric spaces and proved the analog of Banach fixed point theorem. Roughly speaking, a partial metric space is a generalization of a metric spaces in which self distance of some points may not be zero. Matthews [16] discovered this phenomena when he tried to overcome problems of applying metric space techniques in the subfield of computer science: semantics and domain theory (see, e.g., [18, 19]). After the pioneer result of Mathews, remarkably good results have been reported on partial metric spaces (see, e.g., [20-40]).

On the other hand, considering the existence and uniqueness of a fixed point in partially ordered sets initiated a new trend in fixed point theory. The first result in this direction was given by Turinici [41], where he extended Banach contraction principle in partially ordered sets. Ran and Reurings [42] presented some applications of Turinici's theorem to matrix equations. After this intriguing paper, so many exceptionally good results have been revealed in this direction (see, e.g., [43-50]). Worth mentioning, Gnana Bhaskar and Lakshmikantham [44] introduced the notion of a coupled fixed point in the class of partially ordered metric spaces. Motivated by the above history, we devote this paper to prove the existence and uniqueness of coupled fixed points for a new Meir-Keeler type mappings in ordered partial metric spaces.

First, we recall basic definitions and crucial results. Hereafter, we assume that $X \neq \emptyset$ and we use the notation

$$
X^{k}=\underbrace{X \times X \times \cdots \times X}_{k \text {-many }}
$$

Definition 1.1 (see [44]). Let $(X, \leq)$ be a partially ordered set and $F: X \times X \rightarrow X$. F is said to have the mixed monotone property if $F(x, y)$ is monotone nondecreasing in $x$ and is monotone nonincreasing in $y$, that is, for any $x, y \in X$,

$$
\begin{array}{ll}
x_{1} \leq x_{2} \Longrightarrow F\left(x_{1}, y\right) \leq F\left(x_{2}, y\right), & \text { for } x_{1}, x_{2} \in X \\
y_{1} \leq y_{2} \Longrightarrow F\left(x, y_{2}\right) \leq F\left(x, y_{1}\right), & \text { for } y_{1}, y_{2} \in X
\end{array}
$$

Definition 1.2 (see [44]). An element $(x, y) \in X \times X$ is said to be a coupled fixed point of the mapping $F: X \times X \rightarrow X$ if

$$
F(x, y)=x, \quad F(y, x)=y \text {. }
$$

The following two results of Bhaskar and Lakshmikantham in [44] were proved in the context of cone metric spaces in [51]. 
Theorem 1.3 (see [44]). Let $(X, \leq)$ be a partially ordered set and suppose that there is a metric $d$ on $X$ such that $(X, d)$ is a complete metric space. Let $F: X \times X \rightarrow X$ be a continuous mapping having the mixed monotone property on $X$. Assume that there exists $k \in[0,1)$ with

$$
d(F(x, y), F(u, v)) \leq \frac{k}{2}[d(x, u)+d(y, v)], \quad \forall u \leq x, y \leq v
$$

If there exists $x_{0}, y_{0} \in X$ such that $x_{0} \leq F\left(x_{0}, y_{0}\right)$ and $F\left(y_{0}, x_{0}\right) \leq y_{0}$, then there exist $x, y \in X$ such that $x=F(x, y)$ and $y=F(y, x)$.

Theorem 1.4 (see [44]). Let $(X, \leq)$ be a partially ordered set and suppose that there is a metric $d$ on $X$ such that $(X, d)$ is a complete metric space. Let $F: X \times X \rightarrow X$ be a mapping having the mixed monotone property on $\mathrm{X}$. Suppose that $\mathrm{X}$ has the following properties:

(i) if a nondecreasing sequence $\left\{x_{n}\right\} \rightarrow x$, then $x_{n} \leq x$, for all $n$,

(ii) if a nonincreasing sequence $\left\{y_{n}\right\} \rightarrow y_{\text {, then }} y \leq y_{n}$, for all $n$.

Assume that there exists a $k \in[0,1)$ with

$$
d(F(x, y), F(u, v)) \leq \frac{k}{2}[d(x, u)+d(y, v)], \quad \forall u \leq x, y \leq v
$$

If there exists $x_{0}, y_{0} \in X$ such that $x_{0} \leq F\left(x_{0}, y_{0}\right)$ and $F\left(y_{0}, x_{0}\right) \leq y_{0}$, then there exist $x, y \in X$ such that $x=F(x, y)$ and $y=F(y, x)$.

Inspired by Definition 1.1, the following concept of a $g$-mixed monotone mapping was introduced by Lakshmikantham and Ćirić [47].

Definition 1.5 (see [47]). Let $(X, \leq)$ be partially ordered set and $F: X \times X \rightarrow X$ and $g: X \rightarrow X$. $F$ is said to have mixed $g$-monotone property if $F(x, y)$ is monotone $g$-nondecreasing in $x$ and is monotone $g$-nonincreasing in $y$, that is, for any $x, y \in X$,

$$
\begin{aligned}
& g\left(x_{1}\right) \leq g\left(x_{2}\right) \Longrightarrow F\left(x_{1}, y\right) \leq F\left(x_{2}, y\right), \quad \text { for } x_{1}, x_{2} \in X, \\
& g\left(y_{1}\right) \leq g\left(y_{2}\right) \Longrightarrow F\left(x, y_{2}\right) \leq F\left(x, y_{1}\right), \quad \text { for } y_{1}, y_{2} \in X .
\end{aligned}
$$

It is clear that Definition 1.5 reduces to Definition 1.1 when $g$ is the identity.

Definition 1.6 (see [47]). An element $(x, y) \in X \times X$ is called a coupled coincidence point of mappings $F: X \times X \rightarrow X$ and $g: X \rightarrow X$ if

$$
F(x, y)=g(x), \quad F(y, x)=g(y)
$$

and is called a coupled common fixed of $F$ and $g$, if

$$
F(x, y)=g(x)=x, \quad F(y, x)=g(y)=y .
$$


The mappings $F$ and $g$ are said to commute if

$$
g(F(x, y))=F(g(x), g(y))
$$

for all $x, y \in X$.

Very recently, Gordji et al. [31] replaced mixed g-monotone property with a mixed strict gmonotone property and improved the results in [47].

Definition 1.7 (see [31]). Let $(X, \leq)$ be a partially ordered set and $F: X \times X \rightarrow X$ and $g$ : $X \rightarrow X . F$ is said to have the mixed strict $g$-monotone property if $F(x, y)$ is monotone $g$ nondecreasing in $x$ and is monotone $g$-nonincreasing in $y$, that is, for any $x, y \in X$,

$$
\begin{aligned}
& g\left(x_{1}\right)<g\left(x_{2}\right) \Longrightarrow F\left(x_{1}, y\right)<F\left(x_{2}, y\right), \quad \text { for } x_{1}, x_{2} \in X \\
& g\left(y_{1}\right)<g\left(y_{2}\right) \Longrightarrow F\left(x, y_{1}\right)>F\left(x, y_{2}\right),
\end{aligned}
$$

If we replace $g$ with identity map in (1.10), we get the definition of mixed strict monotone property of $F$.

A partial metric is a function $p: X \times X \rightarrow[0, \infty)$ satisfying the following conditions:

(P1) If $p(x, x)=p(x, y)=p(y, y)$, then $x=y$,

(P2) $p(x, y)=p(y, x)$,

(P3) $p(x, x) \leq p(x, y)$,

(P4) $p(x, z)+p(y, y) \leq p(x, y)+p(y, z)$,

for all $x, y, z \in X$. Then $(X, p)$ is called a partial metric space. If $p$ is a partial metric $p$ on $X$, then the function $d_{p}: X \times X \rightarrow[0, \infty)$ given by

$$
d_{p}(x, y)=2 p(x, y)-p(x, x)-p(y, y)
$$

is a metric on $X$. Each partial metric $p$ on $X$ generates a $T_{0}$ topology $\tau_{p}$ on $X$ with a base of the family of open $p$-balls $\left\{B_{p}(x, \varepsilon): x \in X, \varepsilon>0\right\}$, where $B_{p}(x, \varepsilon)=\{y \in X: p(x, y)<p(x, x)+\varepsilon\}$ for all $x \in X$ and $\varepsilon>0$. Similarly, closed $p$-ball is defined as $B_{p}[x, \varepsilon]=\{y \in X: p(x, y) \leq$ $p(x, x)+\varepsilon\}$. For more details see for example $[16,21]$.

Definition 1.8 (see $[16,21,33])$. Let $(X, p)$ be a partial metric space.

(i) A sequence $\left\{x_{n}\right\}$ in $X$ converges to $x \in X$ whenever $\lim _{n \rightarrow \infty} p\left(x, x_{n}\right)=p(x, x)$.

(ii) A sequence $\left\{x_{n}\right\}$ in $X$ is called Cauchy whenever $\lim _{n, m \rightarrow \infty} p\left(x_{n}, x_{m}\right)$ exists (and finite).

(iii) $(X, p)$ is said to be complete if every Cauchy sequence $\left\{x_{n}\right\}$ in $X$ converges, with respect to $\tau_{p}$, to a point $x \in X$, that is, $\lim _{n, m \rightarrow \infty} p\left(x_{n}, x_{m}\right)=p(x, x)$.

(iv) A mapping $f: X \rightarrow X$ is said to be continuous at $x_{0} \in X$ if for each $\varepsilon>0$ there exists $\delta>0$ such that $f\left(B\left(x_{0}, \delta\right)\right) \subset B\left(f\left(x_{0}\right), \varepsilon\right)$. 
Lemma 1.9 (see $[16,21,33])$. Let $(X, p)$ be a partial metric space.

(a) A sequence $\left\{x_{n}\right\}$ is Cauchy if and only if $\left\{x_{n}\right\}$ is a Cauchy sequence in the metric space $\left(X, d_{p}\right)$,

(b) $(X, p)$ is complete if and only if the metric space $\left(X, d_{p}\right)$ is complete. Moreover,

$$
\lim _{n \rightarrow \infty} d_{p}\left(x, x_{n}\right)=0 \Longleftrightarrow \lim _{n \rightarrow \infty} p\left(x, x_{n}\right)=\lim _{n, m \rightarrow \infty} p\left(x_{n}, x_{m}\right)=p(x, x) .
$$

Lemma 1.10 (see [20]). Let $(X, p)$ be a partial metric space. Then

(A) If $p(x, y)=0$ then $x=y$.

(B) If $x \neq y$, then $p(x, y)>0$.

Remark 1.11. If $x=y, p(x, y)$ may not be 0 .

The following two lemmas can be derived from the triangle inequality (P4).

Lemma 1.12 (see [20]). Let $x_{n} \rightarrow z$ as $n \rightarrow \infty$ in a partial metric space $(X, p)$, where $p(z, z)=0$. Then $\lim _{n \rightarrow \infty} p\left(x_{n}, y\right)=p(z, y)$ for every $y \in X$.

Lemma 1.13 (see [36]). Let $\lim _{n \rightarrow \infty} p\left(x_{n}, y\right)=p(y, y)$ and $\lim _{n \rightarrow \infty} p\left(x_{n}, z\right)=p(z, z)$. If $p(y, y)=p(z, z)$ then $y=z$.

Remark 1.14. Limit of a sequence $\left\{x_{n}\right\}$ in a partial metric space $(X, p)$ is not unique.

Example 1.15. Consider $X=[0, \infty)$ with $p(x, y)=\max \{x, y\}$. Then $(X, p)$ is a partial metric space. Clearly, $p$ is not a metric. Observe that the sequence $\left\{1+1 / n^{2}\right\}$ converges both for example to $x=2$ and $y=3$, so no uniqueness of the limit.

We give the partial case of a definition given in [31].

Definition 1.16 (see [31]). Let $(X, p, \leq)$ be a partially ordered partial metric space. Let $F$ : $X \times X \rightarrow X$ and $g: X \rightarrow X$. The mapping $F$ is said to be a $g$-Meir-Keeler type contraction if for any $\varepsilon>0$ there exists a $\delta(\varepsilon)>0$ such that

$$
\varepsilon \leq \frac{1}{2}[p(g(x), g(u))+p(g(y), g(v))]<\varepsilon+\delta(\varepsilon) \Longrightarrow p(F(x, y), F(u, v))<\varepsilon,
$$

for all $x, y, u, v \in X$ with $g(x) \leq g(u), g(y) \geq g(v)$.

If we replace $g$ with the identity in (1.13) and $p$ a metric on $X$, the $F$ is called a MeirKeeler type contraction.

Definition 1.17. Let $(X, p, \leq)$ be a partially ordered partial metric space. Let $F: X \times X \rightarrow X$ and $g: X \rightarrow X$. The mapping $F$ is said to be a strict $g$-Meir-Keeler type contraction if there exists $0<k<1$ such that for any $\varepsilon>0$ there exists a $\delta(\varepsilon)>0$ such that

$$
\varepsilon \leq \frac{k}{2}[p(g(x), g(u))+p(g(y), g(v))]<\varepsilon+\delta(\varepsilon) \Longrightarrow p(F(x, y), F(u, v))<\varepsilon,
$$

for all $x, y, u, v \in X$ with $g(x) \leq g(u), g(y) \geq g(v)$. 
If we replace $g$ with the identity in (1.14) and if $p$ a metric on $X$, the $F$ is called a strict Meir-Keeler type contraction. Further, it can be shown easily that every strict MeirKeeler (resp., strict $g$-Meir-Keeler) type contraction is a Meir-Keeler (resp., $g$-Meir-Keeler) type contraction. defined by

Let $(X, p)$ be a partial metric space. Note that the mappings $\rho_{k}: X^{k} \times X^{k} \rightarrow[0,+\infty)$

$$
\rho_{k}(\mathbf{x}, \mathbf{y}):=p\left(x_{1}, y_{1}\right)+p\left(x_{2}, y_{2}\right)+\cdots+p\left(x_{k}, y_{k}\right)
$$

forms a partial metric on $X^{k}$ where $\mathbf{x}=\left(x_{1}, x_{2}, \ldots, x_{k}\right)$ and $\mathbf{y}=\left(y_{1}, y_{2}, \ldots, y_{k}\right) \in X^{k}$.

The following fact can be derived easily from Definition 1.16.

Lemma 1.18. Let $(X, p, \leq)$ be a partially ordered partial metric space. Let $F: X \times X \rightarrow X$ and $g: X \rightarrow X$. If $F$ is a $g$-Meir-Keeler type contraction, then one has

$$
p(F(x, y), F(u, v))<\frac{1}{2}[p(g(x), g(u))+p(g(y), g(v))]
$$

for all $x, y, u, v \in X$ with $g(x)<g(u), g(y) \geq g(v)$ or $g(x) \leq g(u), g(y)>g(v)$.

Proof. Without loss of generality, suppose that $g(x)<g(u)$ and $g(y) \geq g(v)$ where $x, y, u, v \in X$. It is clear that $p(g(x), g(u))+p(g(y), g(v))>0$. Set $\varepsilon=(1 / 2)[p(g(x), g(u))+$ $p(g(y), g(v))]>0$. Since $F$ is a $g$-Meir-Keeler type contraction, then, for this $\varepsilon$, there exits $\delta=\delta(\varepsilon)>0$ such that

$$
\varepsilon \leq \frac{1}{2}\left[p\left(g\left(x_{0}\right), g\left(u_{0}\right)\right)+p\left(g\left(y_{0}\right), g\left(v_{0}\right)\right)\right]<\varepsilon+\delta \Longrightarrow p\left(F\left(x_{0}, y_{0}\right), F\left(u_{0}, v_{0}\right)\right)<\varepsilon,
$$

for all $x_{0}, y_{0}, u_{0}, v_{0} \in X$ with $g\left(x_{0}\right)<g\left(u_{0}\right)$ and $g\left(y_{0}\right) \geq g\left(v_{0}\right)$. The result follows by choosing $x=x_{0}, y=y_{0}, u=u_{0}, z=z_{0}$, that is,

$$
p(F(x, y), F(u, v))<\frac{1}{2}[p(g(x), g(u))+p(g(y), g(v))] .
$$

Remark 1.19. Let $(X, p, \leq)$ be a partially ordered partial metric space. Let $F: X \times X \rightarrow X$ and $g: X \rightarrow X$. If $F$ is a strict $g$-Meir-Keeler type contraction, then we have

$$
p(F(x, y), F(u, v))<\frac{k}{2}[p(g(x), g(u))+p(g(y), g(v))]
$$

for all $x, y, u, v \in X$ with $g(x)<g(u), g(y) \geq g(v)$ or $g(x) \leq g(u), g(y)>g(v)$.

Proof. The proof is similar to Lemma 1.18 above.

\section{Existence of Coupled Fixed Points}

The following theorem is our first main result. 
Theorem 2.1. Let $(X, p, \leq)$ be a partially ordered partial metric space. Suppose that $X$ has the following properties:

(a) if $\left\{x_{n}\right\}$ is a sequence such that $x_{n+1}>x_{n}$ for each $n=1,2, \ldots$ and $x_{n} \rightarrow x$, then $x_{n}<x$ for each $n=1,2, \ldots$,

(b) if $\left\{y_{n}\right\}$ is a sequence such that $y_{n+1}<y_{n}$ for each $n=1,2, \ldots$ and $y_{n} \rightarrow y$, then $y_{n}>y$ for each $n=1,2, \ldots$.

Let $g: X \rightarrow X$ and $F: X^{2} \rightarrow X$ be mappings such that $F(X \times X) \subset g(X)$ and $g(X)$ is a complete subspace of $(X, p)$. Suppose that $F$ satisfies the following conditions:

(i) F has the mixed strict g-monotone property,

(ii) $F$ is a g-Meir-Keeler type contraction,

(iii) there exist $x_{0}, y_{0} \in X$ such that

$$
g\left(x_{0}\right)<F\left(x_{0}, y_{0}\right), \quad g\left(y_{0}\right) \geq F\left(y_{0}, x_{0}\right) .
$$

Then $F$ and $g$ have a coupled coincidence point, that is, there exist $x, y \in X$ such that

$$
F(x, y)=g(x), \quad F(y, x)=g(y) .
$$

Proof. Let $(x, y)=\left(x_{0}, y_{0}\right) \in X^{2}$ be such that $g\left(x_{0}\right)<F\left(x_{0}, y_{0}\right)$ and $g\left(y_{0}\right) \geq F\left(y_{0}, x_{0}\right)$. We construct the sequence $\left\{x_{n}\right\}$ and $\left\{y_{n}\right\}$ in the following way. Due to the assumption $F(X \times X) \subset$ $g(X)$, we are able to choose $\left(x_{1}, y_{1}\right) \in X^{2}$ such that $g\left(x_{1}\right)=F\left(x_{0}, y_{0}\right)$ and $g\left(y_{1}\right)=F\left(y_{0}, x_{0}\right)$. By repeating the same argument, we can choose $\left(x_{2}, y_{2}\right) \in X^{2}$ such that $g\left(x_{2}\right)=F\left(x_{1}, y_{1}\right)$ and $g\left(y_{2}\right)=F\left(y_{1}, x_{1}\right)$. Inductively, we observe that

$$
g\left(x_{n+1}\right)=F\left(x_{n}, y_{n}\right), \quad g\left(y_{n+1}\right)=F\left(y_{n}, x_{n}\right) \quad \forall n=0,1,2, \ldots
$$

We claim that, for all $n \geq 2$

$$
\begin{gathered}
\cdots>g\left(x_{n}\right)>g\left(x_{n-1}\right)>\cdots>g\left(x_{1}\right)>g\left(x_{0}\right), \\
\cdots<g\left(y_{n}\right)<g\left(y_{n-1}\right)<\cdots<g\left(y_{1}\right) \leq g\left(y_{0}\right) .
\end{gathered}
$$

We will use the mathematical induction to show (2.4). By assumption (iii), we have

$$
g\left(x_{0}\right)<F\left(x_{0}, y_{0}\right)=g\left(x_{1}\right), \quad g\left(y_{0}\right) \geq F\left(y_{0}, x_{0}\right)=g\left(y_{1}\right)
$$

Assume that the inequalities in (2.4) hold for some $n \geq 2$. Regarding the mixed $g$-strict monotone property of $F$, we have

$$
g\left(x_{n-1}\right)<g\left(x_{n}\right) \Longrightarrow\left\{\begin{array}{l}
F\left(x_{n-1}, y_{n-1}\right)<F\left(x_{n}, y_{n-1}\right) \\
F\left(y_{n-1}, x_{n-1}\right)>F\left(y_{n-1}, x_{n}\right)
\end{array}\right.
$$


By repeating the same arguments, we observe that

$$
g\left(y_{n-1}\right)>g\left(y_{n}\right) \Longrightarrow\left\{\begin{array}{l}
F\left(x_{n}, y_{n-1}\right)<F\left(x_{n}, y_{n}\right) \\
F\left(y_{n-1}, x_{n}\right)>F\left(y_{n}, x_{n}\right)
\end{array}\right.
$$

Combining the above inequalities, together with (2.3), we get

$$
\begin{aligned}
& g\left(x_{n}\right)=F\left(x_{n-1}, y_{n-1}\right)<F\left(x_{n}, y_{n}\right)=g\left(x_{n+1}\right), \\
& g\left(y_{n}\right)=F\left(y_{n-1}, x_{n-1}\right)>F\left(y_{n}, x_{n}\right)=g\left(y_{n+1}\right) .
\end{aligned}
$$

So, (2.4) holds for all $n \geq 2$. Set

$$
\Delta_{n}=p\left(g\left(x_{n}\right), g\left(x_{n+1}\right)\right)+p\left(g\left(y_{n}\right), g\left(y_{n+1}\right)\right) .
$$

Taking Lemma 1.18 and (2.4) into account, we get

$$
\begin{aligned}
p\left(g\left(x_{n}\right), g\left(x_{n+1}\right)\right) & =p\left(F\left(x_{n-1}, y_{n-1}\right), F\left(x_{n}, y_{n}\right)\right) \\
& <\frac{1}{2} p\left(g\left(x_{n-1}\right), g\left(x_{n}\right)\right)+p\left(g\left(y_{n-1}\right), g\left(y_{n}\right)\right) \\
p\left(g\left(y_{n}\right), g\left(y_{n+1}\right)\right) & =p\left(F\left(y_{n-1}, x_{n-1}\right), F\left(y_{n}, x_{n}\right)\right) \\
& <\frac{1}{2} p\left(g\left(x_{n-1}\right), g\left(x_{n}\right)\right)+p\left(g\left(y_{n-1}\right), g\left(y_{n}\right)\right) .
\end{aligned}
$$

If we add the previous two inequalities side by side, we obtain that $\Delta_{n}<\Delta_{n-1}$. Hence, $\left\{\Delta_{n}\right\}$ is monotone decreasing sequence in $\mathbb{R}$. Since the sequence $\left\{\Delta_{n}\right\}$ is bounded below, there exists $L \geq 0$ such that $\lim _{n \rightarrow \infty} \Delta_{n}=L$.

We prove $L=0$. Suppose on the contrary that $L \neq 0$. Thus, there is a positive integer $k$ such that for any $n \geq k$, we have

$$
\varepsilon \leq \frac{\Delta_{n}}{2}=\frac{1}{2}\left[p\left(g\left(x_{n}\right), g\left(x_{n+1}\right)\right)+p\left(g\left(y_{n}\right), g\left(y_{n+1}\right)\right)\right]<\varepsilon+\delta(\varepsilon),
$$

where $\varepsilon=L / 2$ and $\delta(\varepsilon)$ is chosen by (ii). In particular, for $n=k$, we have

$$
\varepsilon \leq \frac{\Delta_{k}}{2}=\frac{1}{2}\left[p\left(g\left(x_{k}\right), g\left(x_{k+1}\right)\right)+p\left(g\left(y_{k}\right), g\left(y_{k+1}\right)\right)\right]<\varepsilon+\delta(\varepsilon) .
$$

Regarding the assumption (iii) together with (2.12) and (2.4), we have

$$
p\left(F\left(x_{k}, y_{k}\right), F\left(x_{k+1}, y_{k+1}\right)\right)<\varepsilon,
$$

which is equivalent to

$$
p\left(g\left(x_{k+1}\right), g\left(x_{k+2}\right)\right)<\varepsilon
$$


Similarly, we have

$$
p\left(g\left(y_{k+1}\right), g\left(y_{k+2}\right)\right)<\varepsilon .
$$

Summing the two above inequalities

$$
\frac{\Delta_{k+1}}{2}=\frac{1}{2}\left[p\left(g\left(x_{k+1}\right), g\left(x_{k+2}\right)\right)+p\left(g\left(y_{k+1}\right), g\left(y_{k+2}\right)\right)\right]<\varepsilon,
$$

which contradicts (2.11) for $n=k+1$. Thus, $\varepsilon=L / 2=0$. That is,

$$
\lim _{n \rightarrow \infty} \Delta_{n}=\lim _{n \rightarrow \infty}\left[p\left(g\left(x_{n}\right), g\left(x_{n+1}\right)\right)+p\left(g\left(y_{n}\right), g\left(y_{n+1}\right)\right)\right]=0 .
$$

Consequently, we have

$$
\lim _{n \rightarrow \infty} p\left(g\left(x_{n}\right), g\left(x_{n+1}\right)\right)=0=\lim _{n \rightarrow \infty} p\left(g\left(y_{n}\right), g\left(y_{n+1}\right)\right) .
$$

By condition (P3), we have

$$
p\left(g\left(x_{n}\right), g\left(x_{n}\right)\right) \leq p\left(g\left(x_{n}\right), g\left(x_{n+1}\right)\right)
$$

so letting $n \rightarrow \infty$, we get

$$
\lim _{n \rightarrow \infty} p\left(g\left(x_{n}\right), g\left(x_{n}\right)\right)=0
$$

Analogously, we have

$$
\lim _{n \rightarrow \infty} p\left(g\left(y_{n}\right), g\left(y_{n}\right)\right)=0
$$

We claim that the sequences $\left\{g\left(x_{n}\right)\right\}$ and $\left\{g\left(y_{n}\right)\right\}$ are Cauchy in $(g(X), p)$.

Take an arbitrary $\varepsilon>0$. It follows from (2.17) that there exists $k \in \mathbb{N}$ such that

$$
\frac{1}{2}\left[p\left(g\left(x_{k}\right), g\left(x_{k+1}\right)\right)+p\left(g\left(y_{k}\right), g\left(y_{k+1}\right)\right)\right]<\delta(\varepsilon) .
$$

Without loss of the generality, assume that $\delta(\varepsilon) \leq \varepsilon$ and define the following set

$$
\Pi:=\left\{(x, y) \in X^{2}: p\left(x, g\left(x_{k}\right)\right)+p\left(y, g\left(y_{k}\right)\right)<2(\varepsilon+\delta(\varepsilon)) \text { and } x>g\left(x_{k}\right), y \leq g\left(y_{k}\right)\right\} .
$$

Take $\wedge=(g(X), g(X)) \cap \Pi$. We claim that

$$
(F(p, q), F(q, p)) \in \wedge \quad \forall(x, y)=(g(p), g(q)) \in \wedge \text { where } p, q \in X .
$$


Take $(x, y)=(g(p), g(q)) \in \Pi$. Then, by (2.22) and the triangle inequality (which still holds for partial metrics) we have

$$
\begin{aligned}
\frac{1}{2}\left[p\left(g\left(x_{k}\right), F(p, q)\right)+p\left(g y_{k}, F(q, p)\right)\right] \leq & \frac{1}{2}\left[p\left(g\left(x_{k}\right), g\left(x_{k+1}\right)\right)+p\left(g\left(x_{k+1}\right), F(p, q)\right)\right] \\
& +\frac{1}{2}\left[p\left(g\left(y_{k}\right), g y_{k+1}\right)+p\left(g\left(y_{k+1}\right), F(q, p)\right)\right] \\
= & \frac{1}{2}\left[p\left(g\left(x_{k}\right), g\left(x_{k+1}\right)\right)+p\left(g\left(y_{k}\right), g\left(y_{k+1}\right)\right)\right] \\
& +\frac{1}{2} p\left(F(p, q), F\left(x_{k}, y_{k}\right)\right)+\frac{1}{2} p\left(F\left(y_{k}, x_{k}\right), F(q, p)\right) \\
< & \delta(\varepsilon)+\frac{1}{2} p\left(F(p, q), F\left(x_{k}, y_{k}\right)\right) \\
& +\frac{1}{2} p\left(F\left(y_{k}, x_{k}\right), F(q, p)\right) .
\end{aligned}
$$

We distinguish two cases.

First Case. $(1 / 2)\left[p\left(x, g\left(x_{k}\right)\right)+p\left(y, g\left(y_{k}\right)\right)\right]=(1 / 2)\left[p\left(g(p), g\left(x_{k}\right)\right)+p\left(g(q), g\left(y_{k}\right)\right)\right] \leq \varepsilon$.

By Lemma 1.18 and the definition of $\Pi$, the inequality (2.25) turns into

$$
\begin{aligned}
& \frac{1}{2}\left[p\left(g\left(x_{k}\right), F(p, q)\right)+p\left(g\left(y_{k}\right), F(q, p)\right)\right]< \delta(\varepsilon)+\frac{1}{2} d\left(F(p, q), F\left(x_{k}, y_{k}\right)\right) \\
&+ \frac{1}{2} d\left(F\left(y_{k}, x_{k}\right), F(q, p)\right) \\
&<\delta(\varepsilon)+\frac{1}{2}\left\{\frac{1}{2}\left[p\left(g(p), g\left(x_{k}\right)\right)+p\left(g(q), g\left(y_{k}\right)\right)\right]\right. \\
&\left.+\frac{1}{2}\left[p\left(g\left(y_{k}\right), g(q)\right)+p\left(g\left(x_{k}\right), g(p)\right)\right]\right\} \\
&=\delta(\varepsilon)+\frac{1}{2}\left[p\left(g(p), g\left(x_{k}\right)\right)+p\left(g(q), g\left(y_{k}\right)\right)\right] \\
& \leq \delta(\varepsilon)+\varepsilon .
\end{aligned}
$$

Second Case. $\varepsilon<(1 / 2)\left[p\left(x, g\left(x_{k}\right)\right)+p\left(y, g\left(y_{k}\right)\right)\right]=(1 / 2)\left[p\left(g(p), g\left(x_{k}\right)\right)+p(g(q)\right.$, $\left.\left.g\left(y_{k}\right)\right)\right]<\varepsilon+\delta(\varepsilon)$.

In this case, we have

$$
\varepsilon<\frac{1}{2}\left[p\left(g(p), g\left(x_{k}\right)\right)+p\left(g(q), g\left(y_{k}\right)\right)\right]<\varepsilon+\delta(\varepsilon) .
$$


Since $x=g p>g x_{k}$ and $y=g q \leq g y_{k}$, by (ii), we get

$$
p\left(F(p, q), F\left(x_{k}, y_{k}\right)\right)<\varepsilon
$$

Also, we have

$$
\varepsilon<\frac{1}{2}\left[p\left(g y_{k}, g q\right)+p\left(g x_{k}, g p\right)\right]<\varepsilon+\delta(\varepsilon)
$$

Since $x=g(p)>g\left(x_{k}\right)$ and $y=g(q) \leq g\left(y_{\mathrm{k}}\right)$, by (ii), we get

$$
p\left(F\left(y_{k}, x_{k}\right), F(q, p)\right)<\varepsilon
$$

Thus, combining (2.25), (2.28) and (2.30), we obtain

$$
\frac{1}{2}\left[p\left(g\left(x_{k}\right), F(p, q)\right)+p\left(g\left(y_{k}\right), F(q, p)\right)\right]<\varepsilon+\delta(\varepsilon) .
$$

On the other hand, using (i), it is obvious that

$$
F(p, q)>g\left(x_{k}\right), \quad F(q, p) \leq g\left(y_{k}\right) .
$$

We conclude that $(F(p, q), F(q, p)) \in \Pi$. Since $F(X \times X) \subset g(X)$, so

$$
(F(p, q), F(q, p)) \in \wedge
$$

that is, (2.24) holds. By (2.22), we have $\left(g\left(x_{k+1}\right), g\left(y_{k+1}\right)\right) \in \wedge$. This implies with (2.24) that

$$
\begin{aligned}
\left(g\left(x_{k+1}\right), g\left(y_{k+1}\right)\right) \in \wedge & \Longrightarrow\left(F\left(x_{k+1}, y_{k+1}\right), F\left(y_{k+1}, x_{k+1}\right)\right)=\left(g\left(x_{k+2}\right), g\left(y_{k+2}\right)\right) \in \wedge \\
& \Longrightarrow\left(F\left(x_{k+2}, y_{k+2}\right), F\left(y_{k+2}, x_{k+2}\right)\right)=\left(g\left(x_{k+3}\right), g\left(y_{k+3}\right)\right) \in \wedge \\
& \Longrightarrow \cdots \Longrightarrow\left(g\left(x_{n}\right), g\left(y_{n}\right)\right) \in \wedge \Longrightarrow \cdots
\end{aligned}
$$

Then, for all $n>k$, we have $\left(g x_{n}, g y_{n}\right) \in \wedge$. This implies that for all $n, m>k$, we have

$$
\begin{aligned}
p\left(g\left(x_{n}\right), g\left(x_{m}\right)\right)+p\left(g\left(y_{n}\right), g\left(y_{m}\right)\right) \leq & p\left(g\left(x_{n}\right), g\left(x_{k}\right)\right)+p\left(g\left(y_{n}\right), g\left(y_{k}\right)\right) \\
& +p\left(g\left(x_{k}\right), g\left(x_{m}\right)\right)+p\left(g\left(y_{k}\right), g\left(y_{m}\right)\right) \\
< & 4(\varepsilon+\delta(\varepsilon)) \leq 8 \varepsilon .
\end{aligned}
$$


Thus, the sequences $\left\{g\left(x_{n}\right)\right\}$ and $\left\{g\left(y_{n}\right)\right\}$ are Cauchy in $(g(X), p)$. By Lemma 1.9, $\left\{g\left(x_{n}\right)\right\}$ and $\left\{g\left(y_{n}\right)\right\}$ are also Cauchy in $\left(g(X), d_{p}\right)$. Again by Lemma 1.9, $\left.\left(g(X), d_{p}\right)\right)$ is complete. Thus, there exist $x, y \in X$ such that by using (2.20) and (2.21), we arrive at

$$
\begin{aligned}
& \lim _{n \rightarrow \infty} d_{p}\left(g(x), g\left(x_{n}\right)\right)=0 \Longleftrightarrow p(g(x), g(x))=\lim _{n \rightarrow \infty} p\left(g(x), g\left(x_{n}\right)\right)=\lim _{n \rightarrow \infty} p\left(g\left(x_{n}\right), g\left(x_{n}\right)\right)=0, \\
& \lim _{n \rightarrow \infty} d_{p}\left(g(y), g\left(y_{n}\right)\right)=0 \Longleftrightarrow p(g(y), g(y))=\lim _{n \rightarrow \infty} p\left(g(y), g\left(y_{n}\right)\right)=\lim _{n \rightarrow \infty} p\left(g\left(y_{n}\right), g\left(y_{n}\right)\right)=0 .
\end{aligned}
$$

Since the sequences $\left\{g\left(x_{n}\right)\right\}$ and $\left\{g\left(y_{n}\right)\right\}$ are monotone increasing and monotone decreasing, respectively, by properties (a) and (b), we conclude that

$$
g\left(x_{n}\right)<g(x), \quad g\left(y_{n}\right)>g(y),
$$

for each $n \geq 0$. Therefore, having in mind that $F$ is a $g$-Meir-Keeler type contraction, by (2.37) and Lemma 1.18, we get

$$
p\left(g\left(x_{n+1}\right), F(x, y)\right)=p\left(F\left(x_{n}, y_{n}\right), F(x, y)\right)<\frac{1}{2}\left[p\left(g\left(x_{n}\right), g(x)\right)+p\left(g\left(y_{n}\right), g(y)\right)\right] .
$$

From (2.36), by Lemma 1.12, we obtain

$$
p(g(x), F(x, y))=\lim _{n \rightarrow \infty} p\left(g\left(x_{n+1}\right), F(x, y)\right) \leq \frac{1}{2} \lim _{n \rightarrow \infty}\left[p\left(g\left(x_{n}\right), g(x)\right)+p\left(g\left(y_{n}\right), g(y)\right)\right]=0,
$$

so $F(x, y)=g(x)$. Analogously we get $F(y, x)=g(y)$.

Remark 2.2. We remak that Theorem 2.1 has been proved recently in [31] in the category of partially ordered metric spaces. However, they proceed the proof without using the assumptions (a) and (b) stated in our Theorem. They claimed that $g\left(x_{n}\right)<x$ and $g\left(y_{n}\right)>y$ by using the fact that the sequences $\left\{g\left(x_{n}\right)\right\}$ and $\left\{g\left(y_{n}\right)\right\}$ are increasing and decreasing, respectively. In our belief, this step is not true and cannot be achieved without using the assumptions (a) and (b). Actually, this may not be true if the partial ordering, for example, is obtained via nonstrongly minihedral cones.

Corollary 2.3. Let $(X, p, \leq)$ be a complete ordered partial metric space. Suppose that $X$ has the following properties:

(a) if $\left\{x_{n}\right\}$ is a sequence such that $x_{n+1}>x_{n}$ for each $n=1,2, \ldots$ and $x_{n} \rightarrow x$, then $x_{n}<x$ for each $n=1,2, \ldots$,

(b) if $\left\{y_{n}\right\}$ is a sequence such that $y_{n+1}<y_{n}$ for each $n=1,2, \ldots$ and $y_{n} \rightarrow y_{\text {, then }} y_{n}>y$ for each $n=1,2, \ldots$.. 
Let $F: X^{2} \rightarrow X$ be a given mapping. Suppose that $F$ satisfies the following conditions:

(i) F has the mixed strict monotone property,

(ii) $F$ is a Meir-Keeler type contraction,

(iii) there exist $x_{0}, y_{0} \in X$ such that

$$
x_{0}<F\left(x_{0}, y_{0}\right), \quad y_{0} \geq F\left(y_{0}, x_{0}\right) .
$$

Then, $F$ has a coupled fixed point, that is, there exist $x, y \in X$ such that

$$
F(x, y)=x, \quad F(y, x)=y \text {. }
$$

Proof. It follows by taking $g=I_{X}$, the identity mapping on $X$, in Theorem 2.1.

\section{Uniqueness of Coupled Fixed Points}

Let $(X, \leq)$ be a partially ordered set. We endow $X \times X$ by the following order (denoted $\leq_{g}$ )

$$
(u, v) \leq_{g}(x, y) \Longleftrightarrow g(u)<g(x), g(y) \leq g(v), \quad \forall(x, y),(u, v) \in X \times X
$$

Moreover, $(u, v)$ and $(x, y)$ are called $g$-comparable if either $(u, v) \leq_{g}(x, y)$ or $(u, v) \leq_{g}(x, y)$. In case $g=I_{X}$, we shortly say that $(u, v)$ and $(x, y)$ are comparable and denote by $(u, v) \leq$ $(x, y)$. In this section, we will prove the uniqueness of the coupled fixed point.

Theorem 3.1. In addition to the hypotheses of Theorem 2.1, assume that for all non g-comparable points $(x, y),\left(x^{*}, y^{*}\right) \in X^{2}$, there exists $(a, b) \in X^{2}$ such that $(F(a, b), F(b, a))$ is comparable to both $(g(x), g(y))$ and $\left(g\left(x^{*}\right), g\left(y^{*}\right)\right)$. Further, assume that $F$ and $g$ commute and $F$ is a strict $g$-Meir-Keeler type contraction. Then, $F$ and $g$ have a unique coupled common fixed point, that is, there exists $(u, v) \in X^{2}$ such that

$$
u=g(u)=F(u, v), \quad v=g(v)=F(v, u) .
$$

Proof. The set of coupled coincidence points of $F$ and $g$ is not empty due to Theorem 2.1. If $(x, y)$ is the only coupled coincidence point of $F$ and $g$, then commutativity of $F$ and $g$ implies that

$$
g(g(x))=g(F(x, y))=F(g(x), g(y)), \quad g(g(y))=g(F(y, x))=F(g(y), g(x)) .
$$

Hence, $(u, v)=(g(x), g(y))$ is a coupled coincidence point of $F$ and $g$ and by uniqueness we conclude that

$$
F(x, y)=g(x)=x, \quad F(y, x)=g(y)=y .
$$


Now suppose that $(x, y),\left(x^{*}, y^{*}\right) \in X^{2}$ are two coupled coincidence points of $F$ and $g$. We show that $g(x)=g\left(x^{*}\right)$ and $g(y)=g\left(y^{*}\right)$. To this end we distinguish the following two cases.

First Case. $(x, y)$ is $g$-comparable to $\left(x^{*}, y^{*}\right)$ with respect to the ordering in $X^{2}$, where

$$
F(x, y)=g(x), \quad F(y, x)=g(y), \quad F\left(x^{*}, y^{*}\right)=g\left(x^{*}\right), \quad F\left(y^{*}, x^{*}\right)=g\left(y^{*}\right) .
$$

Without loss of the generality, we may assume that

$$
g(x)=F(x, y)<F\left(x^{*}, y^{*}\right)=g\left(x^{*}\right), \quad g(y)=F(y, x) \geq F\left(y^{*}, x^{*}\right)=g\left(y^{*}\right) .
$$

By definition of $\rho_{2}$ and Lemma 1.18 we have

$$
\begin{aligned}
0 & <\rho_{2}\left((g(x), g(y)),\left(g\left(x^{*}\right), g\left(y^{*}\right)\right)\right)=p\left(g(x), g\left(x^{*}\right)\right)+p\left(g\left(y^{*}\right), g(y)\right) \\
& =p\left(F(x, y), F\left(x^{*}, y^{*}\right)\right)+p\left(F\left(y^{*}, x^{*}\right), F(y, x)\right), \\
& <p\left(g(x), g\left(x^{*}\right)\right)+p\left(g\left(y^{*}\right), g(y)\right)=\rho_{2}\left((g(x), g(y)),\left(g\left(x^{*}\right), g\left(y^{*}\right)\right)\right),
\end{aligned}
$$

which is a contradiction. Therefore, we have $(g(x), g(y))=\left(g\left(x^{*}\right), g\left(y^{*}\right)\right)$. Hence

$$
g(x)=g\left(x^{*}\right), \quad g(y)=g\left(y^{*}\right)
$$

Second Case. $(x, y)$ is not $g$-comparable to $\left(x^{*}, y^{*}\right)$.

By assumption, there exists $(a, b) \in X^{2}$ such that $(F(a, b), F(b, a))$ is comparable to both $(g(x), g(y))$ and $\left(g\left(x^{*}\right), g\left(y^{*}\right)\right)$. Then, we have

$$
\begin{array}{ll}
g(x)=F(x, y)<F(a, b), & F\left(x^{*}, y^{*}\right)=g\left(x^{*}\right)<F(a, b), \\
g(y)=F(y, x) \geq F(b, a), & F\left(y^{*}, x^{*}\right)=g\left(y^{*}\right) \geq F(b, a),
\end{array}
$$

Setting $x=x_{0}, y=y_{0}, a=a_{0}, b=b_{0}$, and $x^{*}=x_{0}^{*}, y^{*}=y_{0}^{*}$ as in the proof of Theorem 2.1, we get

$$
\begin{array}{clc}
g\left(x_{n+1}\right)=F\left(x_{n}, y_{n}\right), & g\left(y_{n+1}\right)=\mathrm{F}\left(y_{n}, x_{n}\right) & \forall n=0,1,2, \ldots, \\
g\left(a_{n+1}\right)=F\left(a_{n}, b_{n}\right), & g\left(b_{n+1}\right)=F\left(b_{n}, a_{n}\right) & \forall n=0,1,2, \ldots, \\
g\left(x_{n+1}^{*}\right)=F\left(x_{n}^{*}, y_{n}^{*}\right), & g\left(y_{n+1}^{*}\right)=F\left(y_{n}^{*}, x_{n}^{*}\right) & \forall n=0,1,2, \ldots .
\end{array}
$$

Since $(F(x, y), F(y, x))=(g(x), g(y))=\left(g\left(x_{1}\right), g\left(y_{1}\right)\right)$ is comparable with $(F(a, b), F(b, a))=$ $\left(g\left(a_{1}\right), g\left(b_{1}\right)\right)$, we have $g(x)<g\left(a_{1}\right)$ and $g\left(b_{1}\right) \leq g(y)$. By using that $F$ has the mixed $g$-strict 
monotone property, we observe that $g(x)<g\left(a_{n}\right)$ and $g\left(b_{n}\right) \leq g(y)$ for all $n \geq 1$. Thus, by Remark 1.19 , we get that

$$
\begin{aligned}
p\left(g(x), g\left(a_{n+1}\right)\right)+p\left(g(y), g\left(b_{n+1}\right)\right)= & p\left(F(x, y), F\left(a_{n}, b_{n}\right)\right)+p\left(F\left(b_{n}, a_{n}\right), F(y, x)\right) \\
< & \frac{k}{2}\left[p\left(g(x), g\left(a_{n}\right)\right)+p\left(g(y), g\left(b_{n}\right)\right)\right] \\
& +\frac{k}{2}\left[p\left(g(y), g\left(b_{n}\right)\right)+p\left(g(x), g\left(a_{n}\right)\right)\right] \\
= & k p\left(g(x), g\left(a_{n}\right)\right)+p\left(g(y), g\left(b_{n}\right)\right) .
\end{aligned}
$$

Inductively, we derive that

$$
\left[p\left(g(x), g\left(a_{n+1}\right)\right)+p\left(g(y), g\left(b_{n+1}\right)\right)\right]<k^{n}\left[p\left(g(x), g\left(a_{1}\right)\right)+p\left(g(y), g\left(b_{1}\right)\right)\right]
$$

The right hand side of above inequality tends to zero as $n \rightarrow \infty$. Hence,

$$
\lim _{n \rightarrow \infty}\left[p\left(g(x), g\left(a_{n+1}\right)\right)+p\left(g(y), g\left(b_{n+1}\right)\right)\right]=0 .
$$

Analogously, we get that

$$
\lim _{n \rightarrow \infty}\left[p\left(g\left(x^{*}\right), g\left(a_{n+1}\right)\right)+p\left(g\left(y^{*}\right), g\left(b_{n+1}\right)\right)\right]=0
$$

By the triangle inequality, we have

$$
\begin{aligned}
p\left(g(x), g\left(x^{*}\right)\right) & \leq p\left(g(x), g\left(a_{n+1}\right)\right)+p\left(g\left(x^{*}\right), g\left(a_{n+1}\right)\right)-p\left(g\left(a_{n+1}\right), g\left(a_{n+1}\right)\right) \\
& \leq p\left(g(x), g\left(a_{n+1}\right)\right)+p\left(g\left(x^{*}\right), g\left(a_{n+1}\right)\right) \longrightarrow 0 \text { as } n \longrightarrow \infty, \\
p\left(g(y), g\left(y^{*}\right)\right) & \leq p\left(g(y), g\left(b_{n+1}\right)\right)+p\left(g\left(y^{*}\right), g\left(b_{n+1}\right)\right)-p\left(g\left(b_{n+1}\right), g\left(b_{n+1}\right)\right) \\
& \leq p\left(g(y), g\left(b_{n+1}\right)\right)+p\left(g\left(y^{*}\right), g\left(b_{n+1}\right)\right) \longrightarrow 0 \quad \text { as } n \longrightarrow \infty .
\end{aligned}
$$

Combining all observation above, we get that $p\left(g\left(x^{*}\right), g(x)\right)=0$ and $p\left(g\left(y^{*}\right), g(y)\right)=0$. Therefore,

$$
g(x)=g\left(x^{*}\right), \quad g(y)=g\left(y^{*}\right) .
$$

In both cases above, we have shown that (3.16) holds. Now, let $g(x)=u$ and $g(y)=v$. By the commutativity of $F$ and $g$ with the fact that $g(x)=F(x, y)$ and $F(y, x)=g(y)$, we have

$$
\begin{aligned}
& g(u)=g(g(x))=g(F(x, y))=F(g(x), g(y))=F(u, v), \\
& g(v)=g(g(y))=g(F(y, x))=F(g(y), g(x))=(F v, u) .
\end{aligned}
$$


Thus, $(u, v)$ is a coupled coincidence point of $F$ and $g$. Setting $u=x^{*}$ and $v=y^{*}$ in (3.17). Then, by (3.16) we have

$$
u=g(x)=g\left(x^{*}\right)=g(u), \quad v=g(y)=g\left(y^{*}\right)=g(v) .
$$

From (3.17) we get that

$$
u=g(u)=F(u, v), \quad v=g(v)=F(v, u) .
$$

Hence, the pair $(u, v)$ is the coupled common fixed point of $F$ and $g$.

Finally, we prove the uniqueness of the coupled common fixed point of $F$ and $g$. Actually, if $(z, w)$ is another coupled common fixed point of $F$ and $g$, then

$$
u=g(u)=g(z)=z, \quad v=g(v)=g(w)=w
$$

follows from (3.16).

Remark 3.2. We remark that Theorem 3.1 above has been recently proved in [31] without assuming that the mapping $F$ is a strict $g$-Meir-Keeler contraction. This leads to a gap in the proof of Theorem 2.6 there.

Corollary 3.3. Suppose that all the hypotheses of Corollary 2.3 hold, and further, for all $(x, y)$, $\left(x^{*}, y^{*}\right) \in X^{2}$, there exists $(a, b) \in X^{2}$ that is comparable to $(x, y)$ and $\left(x^{*}, y^{*}\right)$. Further, assume that $F$ is a strict Meir-Keeler type contraction. Then, $F$ has a unique coupled fixed point.

\section{Applications}

Motivated by Suzuki [52] and on the same lines of Theorem 3.1 of [53], one can prove the following result.

Theorem 4.1. Let $(X, p, \leq)$ be a partially ordered partial metric space. Let $F: X^{2} \rightarrow X$ and $g: X \rightarrow$ $X$ be given mappings such that $F\left(X^{2}\right) \subset g(X)$. Assume that there exists a function $\theta$ from $[0,+\infty)$ into itself satisfying the following:

(I) $\theta(0)=0$ and $\theta(t)>0$ for every $t>0$,

(II) $\theta$ is nondecreasing and right continuous,

(III) for every $\varepsilon>0$, there exists $\delta(\varepsilon)>0$ such that

$$
\varepsilon \leq \theta\left(\frac{1}{2}[p(g x, g u)+p(g y, g v)]\right)<\varepsilon+\delta(\varepsilon) \Longrightarrow \theta p(F(x, y), F(u, v))<\varepsilon,
$$

for all $g x \leq g u$ and $g y \geq g v$.

Then, $F$ is a $g$-Meir-Keeler type function.

The following result is an immediate consequence of Theorems 2.1 and 4.1. 
Corollary 4.2. Let $(X, p, \leq)$ be a partially ordered complete partial metric space. Given $F: X^{2} \rightarrow X$ and $g: X \rightarrow X$ such that $F\left(X^{2}\right) \subset g(X), g(X)$ is a complete subspace and the following hypotheses hold:

(i) F has the mixed g-strict monotone property,

(ii) for every $\varepsilon>0$, there exists $\delta(\varepsilon)>0$ such that

$$
\varepsilon \leq \int_{0}^{(1 / 2)[p(g x, g u)+p(g y, g v)]} \phi(t) d t<\varepsilon+\delta(\varepsilon) \Longrightarrow \int_{0}^{p(F(x, y), F(u, v))} \phi(t) d t<\varepsilon
$$

for all $g x \leq g u$ and $g y \geq g v$, where $\phi:[0,+\infty) \rightarrow[0,+\infty)$ is a locally integrable function satisfying $\int_{0}^{s} \phi(t) d t>0$ for all $s>0$,

(iii) there exist $x_{0}, y_{0} \in X$ such that

$$
g x_{0}<F\left(x_{0}, y_{0}\right), \quad g y_{0} \geq F\left(y_{0}, x_{0}\right)
$$

Assume that the hypotheses (a) and (b) given in Theorem 2.1 hold. Then, F and g have a coupled coincidence point.

To end this paper, we give the following corollary.

Corollary 4.3. Let $(X, p, \leq)$ be a partially ordered partial metric space. Given $F: X^{2} \rightarrow X$ and $g: X \rightarrow X$ such that $F\left(X^{2}\right) \subset g(X), g(X)$ is a complete subspace and the following hypotheses hold:

(i) F has the mixed g-strict monotone property,

(ii) for all $g x \leq g u$ and $g y \geq g v$,

$$
\int_{0}^{p(F(x, y), F(u, v))} \phi(t) d t \leq k \int_{0}^{(1 / 2)[p(g x, g u)+p(g y, g v)]} \phi(t) d t
$$

where $k \in(0,1)$ and $\phi$ is a locally integrable function from $[0,+\infty)$ into itself satisfying $\int_{0}^{s} \phi(t) d t>0$ for all $s>0$,

(iii) there exist $x_{0}, y_{0} \in X$ such that

$$
g x_{0}<F\left(x_{0}, y_{0}\right), \quad g y_{0} \geq F\left(y_{0}, x_{0}\right)
$$

Assume that the hypotheses (a) and (b) of Theorem 2.1 hold. Then, F and $g$ have a coupled coincidence point.

Proof. For all $\varepsilon>0$, we take $\delta(\varepsilon)=(1 / k-1) \varepsilon$ and we apply Corollary 4.2. 


\section{References}

[1] H. Ni, L.-X. Tian, and X. Liu, "Positive almost periodic solution on a nonlinear differential equation," Mathematical Problems in Engineering, vol. 2011, Article ID 567319, 10 pages, 2011.

[2] T. Jitpeera and P. Kumam, "Hybrid algorithms for minimization problems over the solutions of generalized mixed equilibrium and variational inclusion problems," Mathematical Problems in Engineering, vol. 2011, Article ID 648617, 25 pages, 2011.

[3] X. Yang, Y.-C. Liou, and Y. Yao, "Finding minimum norm fixed point of nonexpansive mappings and applications," Mathematical Problems in Engineering, vol. 2011, Article ID 106450, 13 pages, 2011.

[4] L.-L. Huang, L. Xiao, and Z.-H. Wei, "Efficient and effective total variation image super-resolution: a preconditioned operator splitting approach," Mathematical Problems in Engineering, vol. 2011, Article ID 380807, 20 pages, 2011.

[5] Z. Cao, C. Yuan, D. Jiang, and X. Wang, "A note on periodic solutions of second order nonautonomous singular coupled systems," Mathematical Problems in Engineering, vol. 2010, Article ID 458918, 15 pages, 2010.

[6] S.-J. Chern and P.-C. Huang, "On the existence of a weak solution of a half-cell model for PEM fuel cells," Mathematical Problems in Engineering, vol. 2010, Article ID 701096, 16 pages, 2010.

[7] R. Caballero-Águila, A. Hermoso-Carazo, and J. Linares-Pérez, "A new estimation algorithm from measurements with multiple-step random delays and packet dropouts," Mathematical Problems in Engineering, vol. 2010, Article ID 258065, 18 pages, 2010.

[8] S. Wu and C. Huang, "Two-step relaxation Newton method for nonsymmetric algebraic Riccati equations arising from transport theory," Mathematical Problems in Engineering, vol. 2009, Article ID 783920, 17 pages, 2009.

[9] L. Wang, Y.-J. Chen, and R.-C. Du, "Hybrid iteration method for common fixed points of a finite family of nonexpansive mappings in Banach spaces," Mathematical Problems in Engineering, vol. 2009, Article ID 678519, 9 pages, 2009.

[10] J. Wang, X. Xiang, and W. Wei, "Periodic solutions of semilinear impulsive periodic system with time-varying generating operators on Banach space," Mathematical Problems in Engineering, vol. 2008, Article ID 183489, 15 pages, 2008.

[11] K. Balachandran and A. Leelamani, "Null controllability of neutral evolution integrodifferential systems with infinite delay," Mathematical Problems in Engineering, vol. 2006, Article ID 45468, 18 pages, 2006.

[12] K. Balachandran and J. Y. Park, "Existence of solutions and controllability of nonlinear integrodifferential systems in Banach spaces," Mathematical Problems in Engineering, no. 1-2, pp. 65-79, 2003.

[13] K. N. Murty, G. W. Howell, and G. V. R. L. Sarma, "Two (multi) point nonlinear Lyapunov systems associated with an $n$th order nonlinear system of differential equations-existence and uniqueness," Mathematical Problems in Engineering, vol. 6, no. 4, pp. 395-410, 2000.

[14] D. P. Mandic and S. L. Goh, Complex Valued Nonlinear Adaptive Filters: Noncircularity, Widely Linear and Neural Models, Adaptive and Learning Systems for Signal Processing, Communications, and Control, John Wiley \& Sons, 2009.

[15] D. P. Mandic, M. Golz, A. Kuh, D. Obradovic, and T. Tanaka, Eds., Signal Processing Techniques for Knowledge Extraction and Information Fusion, Springer, 2008.

[16] S. G. Matthews, "Partial metric topology," in Papers on General Topology and Applications (Flushing, NY, 1992), vol. 728 of Annals of the New York Academy of Sciences, pp. 183-197, New York Academy of Sciences, New York, NY, USA, 1994.

[17] S. Banach, "Sur les opérations dans les ensembles abstraits et leur applications aux équations intégrales," Fundamenta Mathematicae, vol. 3, pp. 133-181, 1922.

[18] R. D. Kopperman, S. G. Matthews, and H. Pajoohesh, "What do partial metrics represent?" in Proceedings of the 19th Summer Conference on Topology and its Applications, University of CapeTown, 2004.

[19] H.-P. A. Künzi, H. Pajoohesh, and M. P. Schellekens, "Partial quasi-metrics," Theoretical Computer Science, vol. 365, no. 3, pp. 237-246, 2006.

[20] T. Abedelljawad, E. Karapınar, and K. Taş, “Existence and uniqueness of common fixed point on partial metric spaces," Applied Mathematics Letters, vol. 24, pp. 1894-1899, 2011.

[21] I. Altun and A. Erduran, "Fixed point theorems for monotone mappings on partial metric spaces," Fixed Point Theory and Applications, vol. 2011, Article ID 508730, 10 pages, 2011.

[22] I. Altun, F. Sola, and H. Simsek, "Generalized contractions on partial metric spaces," Topology and Its Applications, vol. 157, no. 18, pp. 2778-2785, 2010. 
[23] H. Aydi, "Some coupled fixed point results on partial metric spaces," International Journal of Mathematics and Mathematical Sciences, vol. 2011, Article ID 647091, 11 pages, 2011.

[24] H. Aydi, "Some fixed point results in ordered partial metric spaces," Journal of Nonlinear Sciences and Its Applications, vol. 4, no. 3, pp. 210-217, 2011.

[25] H. Aydi, "Fixed point results for weakly contractive mappings in ordered partial metric spaces," Journal of Advanced Mathematical Studies, vol. 4, no. 2, pp. 1-12, 2011.

[26] H. Aydi, "Fixed point theorems for generalized weakly contractive condition in ordered partial metric spaces," Journal of Nonlinear Analysis and Optimization, vol. 2, no. 2, pp. 33-48, 2011.

[27] H. Aydi, "Common fixed point results for mappings satisfying $(\psi, \varphi)$-weak contractions in ordered partial metric spaces," International Journal Mathematics and Statistics, vol. 12, no. 2, pp. 53-64, 2012.

[28] H. Aydi, "A common fixed point result by altering distances involving a contractive condition of integral type in partial metric spaces," Accepted in Demonstratio Mathematica. In press.

[29] H. Aydi, E. Karapınar, and W. Shatanawi, "Coupled fixed point results for $(\psi, \varphi)$-weakly contractive condition in ordered partial metric spaces," Computers $\mathcal{E}$ Mathematics with Applications, vol. 62, no. 12, pp. 4449-4460, 2011.

[30] L. Cirić, B. Samet, H. Aydi, and C. Vetro, "Common fixed points of generalized contractions on partial metric spaces and an application," Applied Mathematics and Computation, vol. 218, no. 6, pp. 2398-2406, 2011.

[31] M. E. Gordji, Y. J. Cho, S. Ghods, M. Ghods, and M. H. Dehkordi, "Coupled fixed point theorems for contractions in partially ordered metric spaces and applications," Mathematical Problems in Engineering, vol. 2012, Article ID 150363, 20 pages, 2012.

[32] E. Karapınar, "Weak $\varphi$-contraction is considered on partial metric space," Journal of Computational $\mathcal{E}$ Analysis and Applications, vol. 14, no. 2, pp. 206-210, 2012.

[33] E. Karapinar and I. M. Erhan, "Fixed point theorems for operators on partial metric spaces," Applied Mathematics Letters, vol. 24, no. 11, pp. 1894-1899, 2011.

[34] E. Karapınar, "Generalizations of Caristi Kirk's theorem on partial metric spaces," Fixed Point Theory and Applications, vol. 2011, article 4, 2011.

[35] E. Karapınar and U. Yüksel, "Some common fixed point theorems in partial metric spaces," Journal of Applied Mathematics, vol. 2011, Article ID 263621, 16 pages, 2011.

[36] E. Karapınar, S. Sedghi, N. Shobkolaei, and S. M. Vaezpour, "A common fixed point theorem for cyclic operators on partial metric spaces," FILOMAT, vol. 26, no. 2, pp. 407-414, 2012.

[37] E. Karapinar, "A note on common fixed point theorems in partial metric spaces," Miskolc Mathematical Notes, vol. 12, no. 2, pp. 185-191, 2011.

[38] W. Shatanawi, B. Samet, and M. Abbas, "Coupled fixed point theorems for mixed monotone mappings in ordered partial metric spaces," Mathematical and Computer Modelling, vol. 55, no. 3-4, pp. 680-687, 2012.

[39] T. Abdeljawad, E. Karapınar, and K. Taş, "A generalized contraction principle with control functions on partial metric spaces," Computers and Mathematics with Applications, vol. 63, no. 3, pp. 716-719, 2012.

[40] T. Abdeljawad, "Fixed points for generalized weakly contractive mappings in partial metric spaces," Mathematical and Computer Modelling, vol. 54, no. 11-12, pp. 2923-2927, 2011.

[41] M. Turinici, "Abstract comparison principles and multivariable Gronwall-Bellman inequalities," Journal of Mathematical Analysis and Applications, vol. 117, no. 1, pp. 100-127, 1986.

[42] A. C. M. Ran and M. C. B. Reurings, "A fixed point theorem in partially ordered sets and some applications to matrix equations," Proceedings of the American Mathematical Society, vol. 132, no. 5, pp. 1435-1443, 2004.

[43] R. P. Agarwal, M. A. El-Gebeily, and D. O’Regan, “Generalized contractions in partially ordered metric spaces," Applicable Analysis, vol. 87, no. 1, pp. 109-116, 2008.

[44] T. G. Bhaskar and V. Lakshmikantham, "Fixed point theorems in partially ordered metric spaces and applications," Nonlinear Analysis: Theory, Methods \& Applications, vol. 65, no. 7, pp. 1379-1393, 2006.

[45] V. Berinde and M. Borcut, "Tripled fixed point theorems for contractive type mappings in partially ordered metric spaces," Nonlinear Analysis: Theory, Methods \& Applications, vol. 74, no. 15, pp. 48894897, 2011.

[46] V. Berinde, "Coupled fixed point theorems for generalized symmetric Meir-Keeler contractions in ordered metric spaces," http://arxiv.org/abs/1103.5289.

[47] V. Lakshmikantham and L. Cirić, "Coupled fixed point theorems for nonlinear contractions in partially ordered metric spaces," Nonlinear Analysis: Theory, Methods \& Applications, vol. 70, no. 12, pp. 4341-4349, 2009. 
[48] N. V. Luong and N. X. Thuan, "Coupled fixed points in partially ordered metric spaces and application," Nonlinear Analysis: Theory, Methods \& Applications, vol. 74, no. 3, pp. 983-992, 2011.

[49] H. K. Nashine and B. Samet, "Fixed point results for mappings satisfying $(\psi, \varphi)$-weakly contractive condition in partially ordered metric spaces," Nonlinear Analysis: Theory, Methods E Applications, vol. 74, no. 6, pp. 2201-2209, 2011.

[50] J. J. Nieto and R. Rodríguez-López, "Contractive mapping theorems in partially ordered sets and applications to ordinary differential equations," Order, vol. 22, no. 3, pp. 223-239, 2005.

[51] E. Karapınar, "Couple fixed point on cone metric spaces," Gazi University Journal of Science, vol. 24, no. 1, pp. 51-58, 2011.

[52] T. Suzuki, "Meir-Keeler contractions of integral type are still Meir-Keeler contractions," International Journal of Mathematics and Mathematical Sciences, vol. 2007, Article ID 39281, 6 pages, 2007.

[53] B. Samet, "Coupled fixed point theorems for a generalized Meir-Keeler contraction in partially ordered metric spaces," Nonlinear Analysis: Theory, Methods \& Applications, vol. 72, no. 12, pp. 4508-4517, 2010 . 


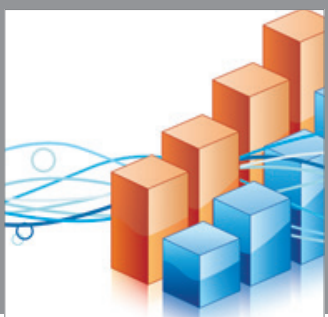

Advances in

Operations Research

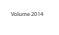

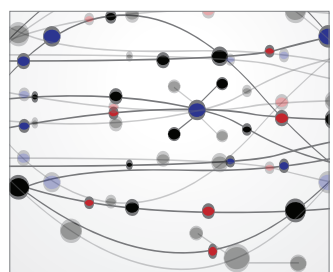

\section{The Scientific} World Journal
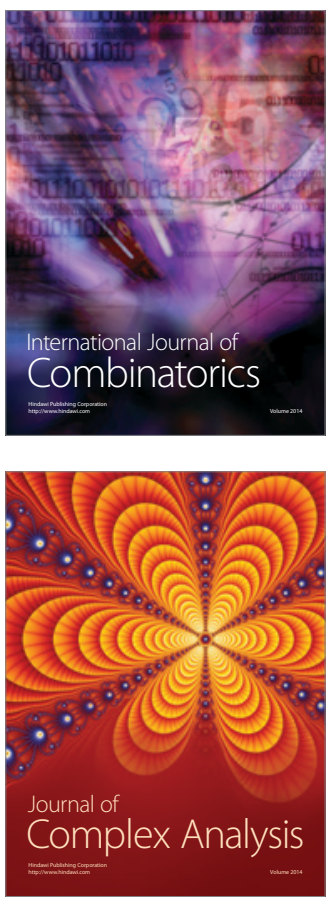

International Journal of

Mathematics and

Mathematical

Sciences
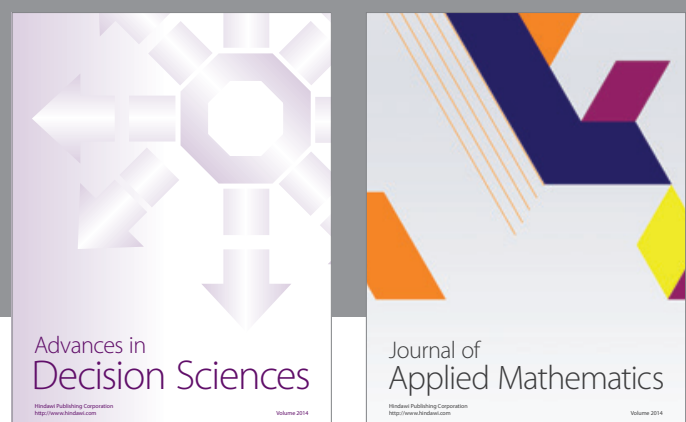

Journal of

Applied Mathematics
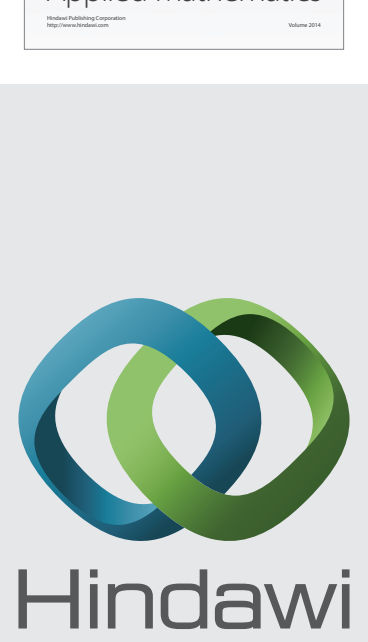

Submit your manuscripts at http://www.hindawi.com
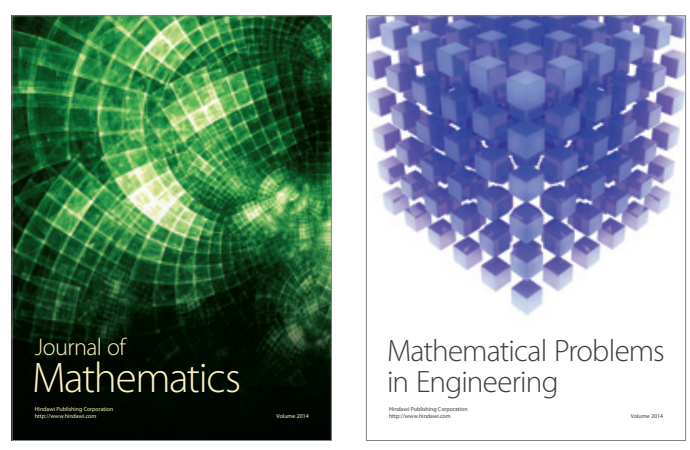

Mathematical Problems in Engineering
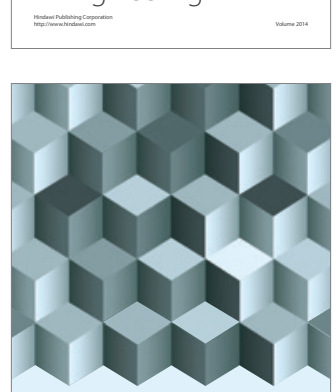

Journal of

Function Spaces
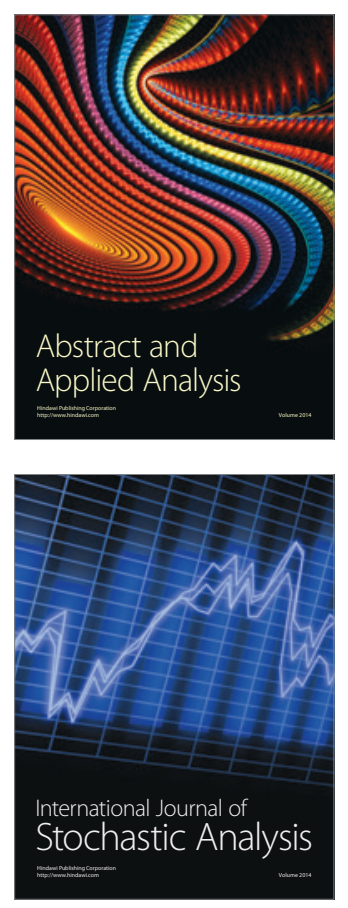

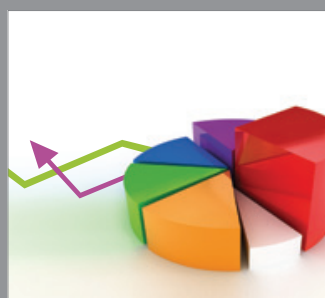

ournal of

Probability and Statistics

Promensencen
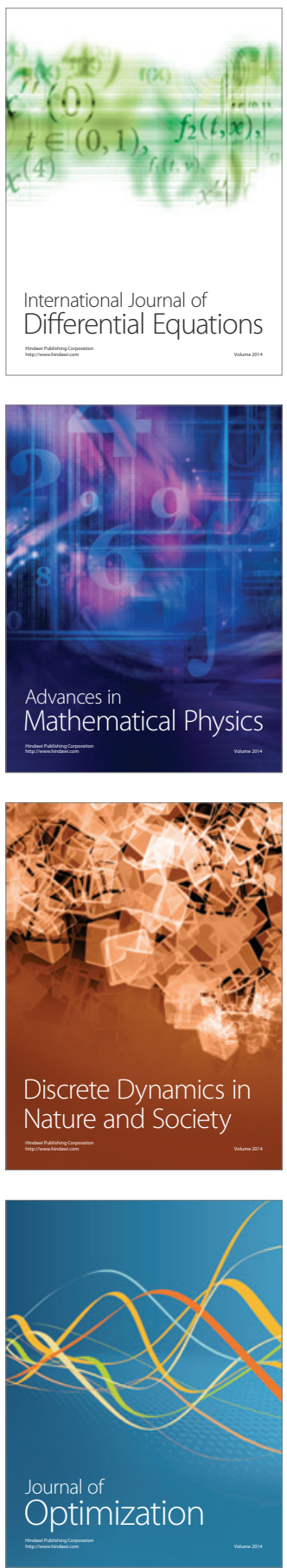